\title{
OXIDATIVE STABILITY AND PHYSICO-CHEMICAL PROPERTIES OF PALM OLEIN
}

\author{
SOEK SIN TEH*; SIAU HUI MAH ${ }^{\star *}$ and RAZNIM ARNI ABD RAZAK*
}

\begin{abstract}
Oxidised oil has been emerged as a root for many chronic diseases. The study was aimed to evaluate the effects of heating on oxidative stability and physico-chemical properties of palm olein. Palm olein was heated to $80^{\circ} \mathrm{C}(\mathrm{P} 80)$ and $120^{\circ} \mathrm{C}$ (P120) up to $12 \mathrm{hr}$. The positional distribution of fatty acids, fatty acid composition (FAC) and iodine value (IV) were analysed using proton-Nuclear Magnetic Resonance ( $\left.{ }^{1} H-N M R\right)$ and carbon-Nuclear Magnetic Resonance $\left({ }^{13} \mathrm{C}-N M R\right)$. The slip melting point (SMP), peroxide value $(P V)$, cloud point (CP) and free fatty acid (FFA) contents of the oil were determined according to MPOB Test Methods. Results implied that the regiospecificity of fatty acids in palm olein, FAC, IV and SMP remained unchanged ( $p>0.05$ ) after both heating treatments for $12 \mathrm{hr}$. The FFA of P80 and P120 were gradually increased, even so, their FFA were within the acceptance level under prolonged heating for $\leq 10 \mathrm{hr}$. The CP of P80 and P120 were gradually increased due to an increase in the amount of FFA in the oils. In general, palm olein exhibited good oxidative stability after being heated for up to $2 \mathrm{hr}$ at $80^{\circ} \mathrm{C}$ and $120^{\circ} \mathrm{C}$ beyond which the oil deteriorated. Overall, this study revealed that palm olein - as a cooking oil - was thermally and oxidatively stable under normal cooking environment.
\end{abstract}

Keywords: cloud point, fatty acid composition, free fatty acid, peroxide value, slip melting point.

Date received: 8 July 2019; Sent for revision: 8 July 2019; Accepted: 2 October 2019; Available online: 16 July 2020.

\section{INTRODUCTION}

Edible oils can be obtained from plant or animal sources. Common edible oils available in the market for cooking are soyabean oil, corn oil, safflower oil, rice bran oil, grapeseed oil, olive oil, sunflower oil, peanut oil, palm oil, fish oil and canola oil. The cooking oils exist in different physical states, including solid, semi-solid or liquid, which depend on the percentage of saturated fatty acids (SFA)

\footnotetext{
Malaysian Palm Oil Board,

6 Persiaran Institusi, Bandar Baru Bangi,

43000 Kajang, Selangor, Malaysia.

E-mail:ssteh@mpob.gov.my

** School of Biosciences, Taylor's University, Lakeside Campus, 47500 Subang Jaya, Selangor, Malaysia.
}

in the oil. Each country has its own preferable edible oils to be used for either cooking or culinary purposes. It is indeed depending very much on the cultivated plants in the countries, and the weather conditions. Heat is applied while cooking dishes at a temperature ranging from $60^{\circ} \mathrm{C}-180^{\circ} \mathrm{C}$, which relies heavily on food preparation. Thus, some types of oils such as polyunsaturated oils, which are susceptible to oxidation, will subsequently produce certain reactive chemicals or even toxic compounds that are hazardous to health (Grootveld et al., 2001). Therefore, prolonged cooking of such oils may be deemed undesirable as it makes the oils unsafe for consumption. Many well-established laboratory methods are available to assess oxidative stabilities of oils relating to peroxide value (PV), iodine value (IV), cloud point (CP) and free fatty acid (FFA) content (Hoekman et al., 2012). 
Previous studies revealed that the detrimental effects of oxidised oils include provoked damage in body, increased oxidative stress (Shafaeizadeh et al., 2011) and caused endothelial dysfunction (Sutherland et al., 2010). Olivero et al. (2010) reported that the thermally oxidised sunflower oil could lead to inflammation, thus giving negative effects on intestinal enzyme activity and gene expression in animal models. The thermally oxidised oil also enhances a lipid peroxidation marker, which is known as thiobarbituric acid relative substance (TBARS), leading to the failure of antioxidant defence mechanisms, as well as tissues injury (Olivero et al., 2010). Furthermore, Grootveld et al. (2001) reviewed that oxidised oil can cause severe diseases such as atherosclerosis, inflammatory joint disease, pathogenic conditions of the digestive tract, mutagenicity, genotoxicity and teratogenicity (Grootveld et al., 2001).

Palm olein, which is derived from the refined, bleached and deodourised palm oil, is the most commonly used cooking oil in Malaysia as the country is the second largest producer of palm oil in the world (Otieno et al., 2016). Palm olein consists of approximately $49 \%$ of SFA and $51 \%$ of unsaturated fatty acids (UFA). The high percentage of SFA in palm olein makes it suitable to be used for deep frying due to its good oxidative stability. Palm olein possesses numerous benefits due to the presence of minor constituents, such as polyphenolics, tocotrienols, tocopherols, carotenoids and phytosterols. Polyphenolics are important plant metabolites that exert antioxidant property (Khurana et al., 2013; Pandey and Rizvi, 2009) and protective health effects by reducing the risks of neuro-degenerative (Scalbert et al., 2005), cancer (Scalbert et al., 2005), cardiovascular (Khurana et al., 2013; Scalbert et al., 2005), diabetes (Pandey and Rizvi, 2009) and osteoporosis (Pandey and Rizvi, 2009) diseases. Grimm et al. (2016) demonstrated the importance of tocotrienols and tocopherols (tocols) in regulating enzymatic activities and gene expression, emphasising the beneficial properties of tocols on neurological function, as well as antioxidant and anti-clotting properties (Grimm et al., 2016). Various studies have proven that foods enriched with carotenoids possess various protective health benefits such as anti-inflammatory (Ciccone et al., 2013) and antioxidant (Ciccone et al., 2013, Stahl et al., 2000) activities as well as often associated with decreasing age-related muscular degeneration and cataracts risks (Mayne, 1996). In 2015, Ogbe et al. highlighted on the significant roles of phytosterols in reducing low density lipoprotein (LDL) and total cholesterol levels, inducing apoptosis in prostate, breast and colon cancer cells, interrupting testosterone metabolism by enzymatic reactions, as well as inhibiting the production of pro-inflammatory and matrix degradation mediators (Ogbe et al., 2015).
Having mentioned all the beneficial effects of the oil, it is important to maintain its quality from external heat and free radicals. Oxidative stability tests have been developed to ensure the quality, shelf-life (Wambura et al., 2008), nutritional quality, palatability and toxicity (Choe and Min, 2006) of edible oils in order to be compliant with legislation and demands of consumers. Different degrees of oxidation of oils generate different hazardous constituents, including primary $\left(1^{\circ}\right)$, secondary $\left(2^{\circ}\right)$ and tertiary $\left(3^{\circ}\right)$ oxidative products such as lipid hydroperoxides, dienes and FFA $\left(1^{\circ}\right.$ oxidation products) (Choe and Min, 2006); alcohols, aldehydes, ketones, hydrocarbons, epoxides and products of polymerisation or copolymerisation ( $2^{\circ}$ oxidation products); peroxyacids and volatile fatty acids ( $3^{\circ}$ oxidation products) (Dabrowska et al., 2015). The adverse effects of oxidised oils causing severe diseases have been widely discussed (Burenjargal and Totani, 2009; Totani and Burenjargal, 2008; Ogino et al., 2015; Shafaeizadeh et al., 2011).

Therefore, oxidation stability of oils should be monitored well in order to minimise any possible hidden risks of chronic diseases. The US Department of Health and Human Services (HHS) recommended that the safe minimum internal temperature for cooking meat and poultry is $165^{\circ} \mathrm{F}$ $\left(74^{\circ} \mathrm{C}\right)$ to ensure food safety whereas the preferred oven temperature for whole meat roasts is $250^{\circ} \mathrm{F}$ $\left(121^{\circ} \mathrm{C}\right)$. Therefore, two cooking temperatures, $80^{\circ} \mathrm{C}$ and $120^{\circ} \mathrm{C}$ were chosen in this study. Our study aimed to determine the effects of the cooking temperatures on the oxidative stability of palm olein. Its quality indicators such as positional distribution of fatty acids, fatty acid composition (FAC), IV, slip melting point (SMP), PV, CP and FFA on palm olein were determined using established test methods.

\section{MATERIALS AND METHODS}

\section{Materials}

Palm olein was purchased from local supermarket in Selangor, Malaysia. Deuterated chloroform $\left(\mathrm{CDCl}_{3}\right)$ was purchased from Sigma Aldrich, Switzerland. All other analytical grade chemicals were purchased from R\&M Chemicals, Malaysia.

\section{Sample Preparation}

Palm olein was heated at $80 \pm 3^{\circ} \mathrm{C}$ (sample denoted as P80) and aliquot oil samples were collected at 2-hr interval for $12 \mathrm{hr}$ and labelled as T0, T2, T4, T6, T8, T10 and T12 for analyses. The steps above were repeated by heating palm olein at $120 \pm 3^{\circ} \mathrm{C}$ (sample denoted as P120). 


\section{Positional Distribution of Fatty Acids, FAC and IV of Samples}

The fatty acid positional distribution in samples and their saturation levels were determined using a Nuclear Magnetic Resonance (NMR) spectrometer (JEOL ECZ-600 MHz) (Teh et al., 2016). About 100 $\mathrm{mg}$ of the samples were dissolved in $0.5 \mathrm{ml}$ of $\mathrm{CDCl}_{3}$ and analysed via quantitative ${ }^{13} \mathrm{C}-\mathrm{NMR}$ and ${ }^{1} \mathrm{H}-\mathrm{NMR}$. The fatty acid positional distribution in the triglycerides of the samples were acquired with specific parameters: 15.0 s of relaxation delay, 8192 of data points, $90^{\circ}$ of pulse angle and spectral width of $1500 \mathrm{~Hz}$ at which the acyl chain carbonyl carbons resonate. The FAC of the samples were detected according to Miyake (1998) with slight modifications as follows: $1500 \mathrm{~Hz}$ of spectral width, 16384 of data points and $1.82 \mathrm{~s}$ of acquisition time. The analyses were performed in triplicate for each sample. The IV of the samples was calculated using data from ${ }^{1} \mathrm{H}-\mathrm{NMR}$ according to AOCS Cd 1c-85: Calculated IV (1998) with some modifications:

$$
\mathrm{IV}=\mathrm{C} 18: 1(0.860)+\mathrm{C} 18: 2(1.732)+\mathrm{C} 18: 3(2.616)
$$

\section{Free Fatty Acids (FFA) Content}

Twenty grams (20 g) of sample was dissolved in $50 \mathrm{ml}$ of neutralised ethanol. The mixture was heated at $40^{\circ} \mathrm{C}$. The mixture was shaken gently and titrated with $0.02 \mathrm{M}$ potassium hydroxide $(\mathrm{KOH})$ solution until permanent pink colour was observed. A blank determination was carried out simultaneously with the sample. The analysis was performed in triplicate for each sample. The FFA content (as wt\% of palmitic acid) was calculated according to AOCS Official Method Ca 5a-40: FFA (2009) as below:

$$
\begin{aligned}
& \text { FFA as palmitic acid, } \mathrm{wt} \%=(25.6 \times \mathrm{M} \times \mathrm{V}) / \mathrm{m} \\
& \text { where M - Molarity of standardised } \mathrm{KOH} \text { (mol } \\
& \text { litre }^{-1} \text { ), } \\
& \mathrm{V} \text { - Volume of } \mathrm{KOH} \text { used }(\mathrm{ml}) \text { and } \\
& \mathrm{m} \text { - Mass of the sample }(\mathrm{g})
\end{aligned}
$$

\section{SMP}

The sample was melted and filled into a capillary tube for approximately $1 \mathrm{~cm}$ from the open end of the capillary tube and kept at $-5^{\circ} \mathrm{C}$ for $24 \mathrm{hr}$. The capillary was then tied to the lowest part of the thermometer and immersed in a temperaturecontrolled water bath. The SMP of the sample was recorded once the oil began to rise in the capillary tube. The analysis was performed in triplicate for each sample according to MPOB Test Method p4.2:2004: Determination of SMP (2004).
CP

$\mathrm{CP}$ of the samples were conducted using MPOB Test Method p4.3:2004: Determination of CP (2004). In brief, the sample was heated at $130^{\circ} \mathrm{C}$ for 5 min, then immediately immersed and cooled in a temperature-controlled water bath. A thermometer was immersed in the sample. The CP of the sample was recorded once the lowest part of the immersed thermometer was no longer visible. The analysis was performed in triplicate for each sample.

PV

One gram ( $1 \mathrm{~g})$ of the sample was dissolved in 50 ml of 3:2 acetic acid:iso-octane solution. Next, $0.5 \mathrm{ml}$ of saturated potassium iodide solution was added into the mixture and shaken gently for $1 \mathrm{~min}$, followed by $30 \mathrm{ml}$ of distilled water. The mixture was then titrated with $0.01 \mathrm{M}$ sodium thiosulphate $\left(\mathrm{Na}_{2} \mathrm{~S}_{2} \mathrm{O}_{3}\right)$ solution with constant vigourous agitation. When the yellow colour of the solution was almost faded, $0.5 \mathrm{ml}$ of $5 \mathrm{~g} \mathrm{litre}^{-1}$ starch solution was added and the titration continued until the blue colour faded. A blank determination was carried out simultaneously with the sample. The analysis was performed in triplicate for each sample. The PV was calculated according to MPOB Test Method p2.3:2004 as below:

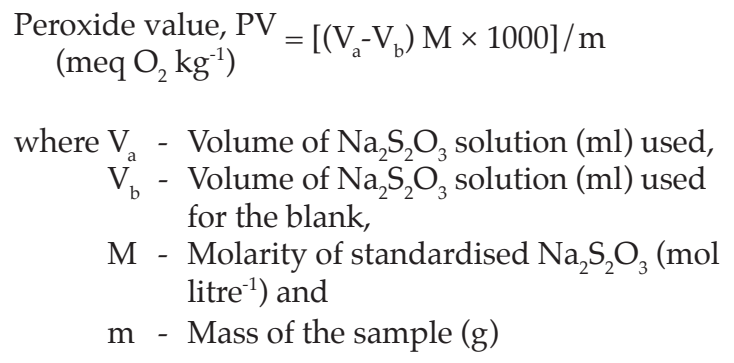

\section{Statistical Analysis}

All data obtained were performed using statistical analysis software, GraphPad Prism 7 and presented as mean \pm standard deviations. The data were analysed by one-way analysis of variance (ANOVA), followed by Tukey's Multiple Comparison Test. Results were considered to be statistically significant when the $p$ value was $<0.05$.

\section{RESULTS AND DISCUSSION}

Oxidative stability and physico-chemical properties of palm olein were examined in this study under two different heating conditions, i.e. $80^{\circ} \mathrm{C}(\mathrm{P} 80)$ and $120^{\circ} \mathrm{C}$ (P120). The positional distribution of fatty acids in the resulting oils were determined using quantitative ${ }^{13} \mathrm{C}$-NMR spectroscopy. The results (Tables $1 a$ and $1 b$ ) indicated that the SFA at the $s n$ 1,3 positions of $\mathrm{P} 80$ ranged from $64.1 \%-67.4 \%$ while 
TABLE 1a. POSITIONAL FATTY ACID COMPOSITIONS (mol $100 \mathrm{~mol}^{-1}$ total fatty acids) OF PALM OLEIN HEATED AT $80^{\circ} \mathrm{C}(\mathrm{P} 80)$ FROM 0 TO $12 \mathrm{hr}$ (T0, T2, T4, T6, T8, T10 and T12)

\begin{tabular}{|c|c|c|c|c|}
\hline \multirow{2}{*}{ Sample } & \multirow{2}{*}{ Types of fatty acids } & \multicolumn{3}{|c|}{ Composition $(\mathrm{mol} \%)$} \\
\hline & & $s n-1,3$ & $s n-2$ & $s n-1,2,3$ \\
\hline \multirow{3}{*}{$\begin{array}{l}\text { Palm olein } \\
\text { (control) }\end{array}$} & SFA & $67.1 \pm 1.2$ & $6.7 \pm 0.3$ & $46.8 \pm 0.8$ \\
\hline & MUFA & $28.1 \pm 1.4$ & $66.3 \pm 0.4$ & $41.0 \pm 1.0$ \\
\hline & PUFA & $4.8 \pm 0.2$ & $27.0 \pm 0.2$ & $12.2 \pm 0.1$ \\
\hline \multirow{3}{*}{ T0 } & SFA & $66.0 \pm 2.1$ & $6.0 \pm 0.8$ & $46.2 \pm 1.2$ \\
\hline & MUFA & $29.5 \pm 3.4$ & $66.5 \pm 0.6$ & $41.7 \pm 2.0$ \\
\hline & PUFA & $4.5 \pm 1.4$ & $27.5 \pm 0.4$ & $12.1 \pm 1.0$ \\
\hline \multirow{3}{*}{$\mathrm{T} 2$} & SFA & $67.4 \pm 1.3$ & $6.8 \pm 1.5$ & $47.2 \pm 1.1$ \\
\hline & MUFA & $27.9 \pm 0.8$ & $67.6 \pm 1.2$ & $41.1 \pm 0.1$ \\
\hline & PUFA & $4.7 \pm 0.8$ & $25.6 \pm 1.8$ & $11.7 \pm 1.1$ \\
\hline \multirow{3}{*}{$\mathrm{T} 4$} & SFA & $67.2 \pm 0.4$ & $8.0 \pm 1.1$ & $47.3 \pm 0.4$ \\
\hline & MUFA & $28.8 \pm 0.2$ & $70.0 \pm 0.7$ & $42.7 \pm 0.2$ \\
\hline & PUFA & $4.0 \pm 0.3$ & $22.0 \pm 0.7$ & $10.0 \pm 0.3$ \\
\hline \multirow{3}{*}{ T6 } & SFA & $64.1 \pm 3.1$ & $6.6 \pm 0.4$ & $45.5 \pm 1.6$ \\
\hline & MUFA & $31.0 \pm 2.2$ & $66.6 \pm 4.6$ & $42.5 \pm 2.6$ \\
\hline & PUFA & $4.9 \pm 1.0$ & $26.8 \pm 4.9$ & $12.0 \pm 1.5$ \\
\hline \multirow{3}{*}{$\mathrm{T} 8$} & SFA & $66.8 \pm 0.6$ & $7.2 \pm 1.9$ & $47.0 \pm 1.2$ \\
\hline & MUFA & $27.2 \pm 0.8$ & $69.2 \pm 4.2$ & $41.2 \pm 1.2$ \\
\hline & PUFA & $6.0 \pm 1.4$ & $23.6 \pm 4.1$ & $11.8 \pm 1.1$ \\
\hline \multirow{3}{*}{$\mathrm{T} 10$} & SFA & $65.7 \pm 1.1$ & $6.6 \pm 0.9$ & $46.5 \pm 0.4$ \\
\hline & MUFA & $29.1 \pm 2.5$ & $67.1 \pm 3.4$ & $41.5 \pm 2.3$ \\
\hline & PUFA & $5.2 \pm 1.4$ & $26.3 \pm 3.6$ & $12.0 \pm 2.0$ \\
\hline \multirow{3}{*}{$\mathrm{T} 12$} & SFA & $65.4 \pm 2.3$ & $6.9 \pm 0.2$ & $46.3 \pm 1.4$ \\
\hline & MUFA & $30.2 \pm 2.2$ & $68.4 \pm 1.9$ & $42.7 \pm 1.1$ \\
\hline & PUFA & $4.4 \pm 0.2$ & $24.7 \pm 1.8$ & $11.0 \pm 0.7$ \\
\hline
\end{tabular}

Note: SFA - saturated fatty acids; MUFA - monounsaturated fatty acids; PUFA - polyunsaturated fatty acids. All data shown $p>0.05$ compared to control.

the UFA at the sn-2 position were $92.0 \%-94.0 \%$. Nevertheless, P120 exhibited $65.8 \%-68.0 \%$ of SFA at $s n-1,3$ positions and $92.1 \%-94.0 \%$ of UFA at $s n-2$ position. The positional distribution of fatty acid profiles amongst aliquot samples of P80 namely T0, T2, T4, T6, T8, T10 and T12 were comparable based on the statistical analysis. Similar trend was observed for P120 after heating at the same time interval. No significant difference $(p>0.05)$ was found between the two sets of palm olein (P80 and P120) and control (without heating treatment). The findings demonstrated that heating palm olein at $80^{\circ} \mathrm{C}$ and $120^{\circ} \mathrm{C}$ did not give any significant effect on the regiospecific distribution of fatty acids as compared to control as no rearrangement of fatty acids was observed. Previous studies indicated that the sn-2 position of fatty acids in oils plays an important role in regulating cholesterol metabolism (Redgrave et al., 1988) while the $s n-1,3$ positions in regulating fat absorption (Small, 1991). These results showed that increasing reaction time and heating temperature did not alter the structure of palm olein, hence, indicating no significant effect on the serum cholesterol level and fat deposition.
The FAC of P80 and P120 (Table 2) were determined by ${ }^{1} \mathrm{H}-\mathrm{NMR}$ spectroscopic method. All of the oils tested showed similar percentages of SFA $(45.3 \%-48.3 \%)$, oleic acid $(39.4 \%-43.8 \%)$, linoleic acid (10.7\%-11.9\%) and linolenic acid (0.2\%$0.4 \%$ ). Both P80 and P120 possessed comparable FAC profiles which were consistent with those via quantitative ${ }^{13} \mathrm{C}-\mathrm{NMR}$ analysis $(p>0.05)$ as compared to the fatty acids at the $s n-1,2,3$ positions of the oils. These identical FAC profiles might be attributable to a slower oxidation rate of palm olein due to its high content of SFA, which would have assisted in counterbalancing the detrimental effects of UFA. This finding was consistent with literature data which revealed that autoxidation and thermal oxidation are highly associated with the degree of unsaturation levels of oils (Brodnitz, 1968; Tian and Dasgupta, 1999); higher amount of UFA will cause a greater rate of oxidation. Therefore, IV is important to evaluate the quality as well as predict the oxidising tendency of oil. The changes in IV of P80 and P120 were insignificant after prolonged heating at $80^{\circ} \mathrm{C}$ and $120^{\circ} \mathrm{C}$, as compared to control (Table 3). The data postulated an equitable balanced 
TABLE 1b. POSITIONAL FATTY ACID COMPOSITIONS (mol $100 \mathrm{~mol}^{-1}$ total fatty acids) OF PALM OLEIN HEATED AT $120^{\circ} \mathrm{C}(\mathrm{P} 120)$ FROM 0 TO $12 \mathrm{hr}$ (T0, T2, T4, T6, T8, T10 and T12)

\begin{tabular}{|c|c|c|c|c|}
\hline \multirow{2}{*}{ Sample } & \multirow{2}{*}{ Types of fatty acids } & \multicolumn{3}{|c|}{ Composition $(\mathrm{mol} \%)$} \\
\hline & & $s n-1,3$ & $s n-2$ & $s n-1,2,3$ \\
\hline \multirow{3}{*}{$\begin{array}{c}\text { Palm olein } \\
\text { (control) }\end{array}$} & SFA & $67.1 \pm 1.2$ & $6.7 \pm 0.3$ & $46.8 \pm 0.8$ \\
\hline & MUFA & $28.1 \pm 1.4$ & $66.3 \pm 0.4$ & $41.0 \pm 1.0$ \\
\hline & PUFA & $4.8 \pm 0.2$ & $27.0 \pm 0.2$ & $12.2 \pm 0.1$ \\
\hline \multirow{3}{*}{ T0 } & SFA & $67.3 \pm 0.7$ & $7.9 \pm 0.9$ & $47.8 \pm 0.8$ \\
\hline & MUFA & $29.3 \pm 0.8$ & $70.4 \pm 3.5$ & $42.8 \pm 0.7$ \\
\hline & PUFA & $3.4 \pm 0.6$ & $21.7 \pm 2.6$ & $9.4 \pm 0.7$ \\
\hline \multirow{3}{*}{$\mathrm{T} 2$} & SFA & $66.6 \pm 0.5$ & $7.6 \pm 0.5$ & $47.4 \pm 0.5$ \\
\hline & MUFA & $29.3 \pm 0.7$ & $71.8 \pm 3.6$ & $43.1 \pm 1.9$ \\
\hline & PUFA & $4.1 \pm 1.1$ & $20.6 \pm 4.1$ & $9.5 \pm 1.7$ \\
\hline \multirow{3}{*}{$\mathrm{T} 4$} & SFA & $66.8 \pm 1.4$ & $6.9 \pm 1.4$ & $46.6 \pm 0.3$ \\
\hline & MUFA & $27.9 \pm 0.6$ & $70.6 \pm 2.6$ & $42.3 \pm 0.4$ \\
\hline & PUFA & $5.3 \pm 0.8$ & $22.5 \pm 1.2$ & $11.1 \pm 0.2$ \\
\hline \multirow{3}{*}{ T6 } & SFA & $66.6 \pm 0.7$ & $7.6 \pm 2.0$ & $46.9 \pm 0.2$ \\
\hline & MUFA & $29.2 \pm 0.6$ & $66.1 \pm 1.2$ & $41.5 \pm 0.6$ \\
\hline & PUFA & $4.2 \pm 1.3$ & $26.3 \pm 0.9$ & $11.6 \pm 0.7$ \\
\hline \multirow{3}{*}{$\mathrm{T} 8$} & SFA & $65.8 \pm 1.9$ & $6.0 \pm 0.4$ & $46.2 \pm 0.5$ \\
\hline & MUFA & $28.8 \pm 2.0$ & $66.8 \pm 4.0$ & $41.2 \pm 2.0$ \\
\hline & PUFA & $5.4 \pm 0.2$ & $27.2 \pm 4.0$ & $12.6 \pm 1.6$ \\
\hline \multirow{3}{*}{$\mathrm{T} 10$} & SFA & $66.7 \pm 0.7$ & $6.1 \pm 0.5$ & $46.7 \pm 0.4$ \\
\hline & MUFA & $28.0 \pm 1.1$ & $67.8 \pm 2.6$ & $41.1 \pm 0.5$ \\
\hline & PUFA & $5.3 \pm 0.9$ & $26.1 \pm 2.2$ & $12.2 \pm 0.2$ \\
\hline \multirow{3}{*}{$\mathrm{T} 12$} & SFA & $68.0 \pm 0.1$ & $7.3 \pm 0.3$ & $47.8 \pm 0.3$ \\
\hline & MUFA & $27.6 \pm 1.1$ & $66.3 \pm 1.6$ & $40.5 \pm 1.4$ \\
\hline & PUFA & $4.4 \pm 1.1$ & $26.4 \pm 1.7$ & $11.7 \pm 1.2$ \\
\hline
\end{tabular}

Note: SFA - saturated fatty acids; MUFA - monounsaturated fatty acids; PUFA - polyunsaturated fatty acids. All data shown $p>0.05$ compared to control.

saturation/unsaturation fat in palm olein which helped decelerating oil deterioration.

Alternately, the oxidative stability of oils can be examined by measuring their FFA contents. Literature data revealed that FFA is more prone to oxidation (Molteberg et al., 1996; Mahesar et al., 2014) compared to that of esterified fatty acids (Kinsella et al., 1978). The FFA contents of P80 and P120 are presented in Figure 1. The results between P80 and control (i.e. $0.051 \pm 0.001)$ were insignificant except for T10 $(0.055 \pm 0.001)$ and T12 $(0.058 \pm 0.003)$ which were heated for $\geq 10 \mathrm{hr}$. The FFA content (calculated as wt $\%$ of palmitic acid) of P80 fell within the acceptable level $(0.1 \mathrm{wt} \%)$ for refined, bleached, deodourised palm olein as stipulated in Palm Oil Refiners Association of Malaysia Standard Specifications for processed palm oil. In contrast, FFA content of P120 was highly associated with the reaction time. Although the FFA content of palm olein heated at $120^{\circ} \mathrm{C}$ for $10 \mathrm{hr}$ was within the acceptance level, the percentage increased to $53.0 \%$ after $10 \mathrm{hr}$ (i.e. $0.101 \pm 0.002$ ) which slightly exceeded the maximum limit $(0.1 \mathrm{wt} \%)$. The results implied that prolonged heating of palm olein for more than
$10 \mathrm{hr}$ at high temperature $\left(120^{\circ} \mathrm{C}\right)$ should be avoided even though palm olein is generally regarded as thermally stable.

The SMP and CP are important parameters for oil quality monitoring in food and cosmetic industries. In addition, $\mathrm{CP}$ can also determine storage stability of an oil. The SMP of palm olein is $16.3^{\circ} \mathrm{C}$, which is consistent with literature data (Siew, 1990). The SMP of both P80 and P120 did not differ significantly even with increasing reaction time and heating temperature compared to the control (Figure 2). Nonetheless, their $\mathrm{CP}$ increased to different extents gradually, with P120 showing more intense changes throughout the treatment period. Also, significant difference was observed between the two sets. A gradual increase of FFA content at $120^{\circ} \mathrm{C}$ in the oils resulted in higher $\mathrm{CP}$ (Figure 3). This was probably due to the higher melting point of the increased FFA present and/or changes of the types of SFA, which in turn increased the crystallisation rate of the oils. For instance, the melting points of lauric acid (C12:0), myristic acid (C14:0), palmitic acid (C16:0) and stearic acid (C18:0) are ranging from $43.0^{\circ} \mathrm{C}-70.0^{\circ} \mathrm{C}$. 
TABLE 2. FATTY ACID COMPOSITION (FAC) OF PALM OLEIN HEATED AT $80^{\circ} \mathrm{C}$ AND $120^{\circ} \mathrm{C}$ FROM 0 TO 12 hr (T0, T2, T4, T6, T8, T10 and T12)

\begin{tabular}{|c|c|c|c|}
\hline \multirow[t]{2}{*}{ Sample } & \multirow{2}{*}{$\begin{array}{l}\text { Types of } \\
\text { fatty acids }\end{array}$} & \multicolumn{2}{|c|}{$\begin{array}{l}\text { Total FAC of test oils } \\
\text { (g } 100 \mathrm{~g}^{-1} \text { total fatty acids) }\end{array}$} \\
\hline & & $80^{\circ} \mathrm{C}$ & $120^{\circ} \mathrm{C}$ \\
\hline \multirow{4}{*}{$\begin{array}{l}\text { Palm olein } \\
\text { (control) }\end{array}$} & C18:1 & \multicolumn{2}{|c|}{$40.0 \pm 0.3$} \\
\hline & C18:2 & \multicolumn{2}{|c|}{$11.8 \pm 0.5$} \\
\hline & C18:3 & \multicolumn{2}{|c|}{$0.4 \pm 0.0$} \\
\hline & SFA & \multicolumn{2}{|c|}{$47.8 \pm 1.2$} \\
\hline \multirow{4}{*}{ T0 } & C18:1 & $41.3 \pm 0.7$ & $41.2 \pm 0.8$ \\
\hline & C18:2 & $11.9 \pm 0.2$ & $11.6 \pm 0.5$ \\
\hline & C18:3 & $0.3 \pm 0.1$ & $0.3 \pm 0.0$ \\
\hline & SFA & $46.5 \pm 1.0$ & $46.9 \pm 0.9$ \\
\hline \multirow{4}{*}{$\mathrm{T} 2$} & C18:1 & $42.0 \pm 1.4$ & $40.8 \pm 0.6$ \\
\hline & C18:2 & $11.8 \pm 1.2$ & $11.7 \pm 0.5$ \\
\hline & C18:3 & $0.3 \pm 0.1$ & $0.3 \pm 0.0$ \\
\hline & SFA & $45.9 \pm 0.5$ & $47.2 \pm 1.0$ \\
\hline \multirow{4}{*}{$\mathrm{T} 4$} & C18:1 & $39.4 \pm 0.6$ & $40.6 \pm 0.8$ \\
\hline & C18:2 & $11.9 \pm 0.3$ & $11.8 \pm 0.4$ \\
\hline & C18:3 & $0.4 \pm 0.1$ & $0.3 \pm 0.1$ \\
\hline & SFA & $48.3 \pm 1.1$ & $47.3 \pm 0.8$ \\
\hline \multirow{4}{*}{ T6 } & C18:1 & $41.0 \pm 0.7$ & $40.2 \pm 0.6$ \\
\hline & C18:2 & $11.5 \pm 0.6$ & $11.5 \pm 0.7$ \\
\hline & C18:3 & $0.2 \pm 0.1$ & $0.3 \pm 0.0$ \\
\hline & SFA & $47.3 \pm 0.9$ & $48.0 \pm 0.8$ \\
\hline \multirow{4}{*}{$\mathrm{T} 8$} & C18:1 & $41.6 \pm 1.1$ & $41.4 \pm 0.4$ \\
\hline & C18:2 & $11.3 \pm 1.0$ & $11.3 \pm 0.8$ \\
\hline & C18:3 & $0.3 \pm 0.1$ & $0.3 \pm 0.0$ \\
\hline & SFA & $46.8 \pm 0.3$ & $47.0 \pm 1.1$ \\
\hline \multirow{4}{*}{$\mathrm{T} 10$} & C18:1 & $40.5 \pm 0.8$ & $41.3 \pm 1.3$ \\
\hline & C18:2 & $11.7 \pm 0.3$ & $11.3 \pm 0.9$ \\
\hline & C18:3 & $0.3 \pm 0.1$ & $0.4 \pm 0.2$ \\
\hline & SFA & $47.5 \pm 0.8$ & $47.0 \pm 0.9$ \\
\hline \multirow{4}{*}{$\mathrm{T} 12$} & C18:1 & $40.8 \pm 0.8$ & $43.8 \pm 1.4$ \\
\hline & C18:2 & $11.8 \pm 0.8$ & $10.7 \pm 1.8$ \\
\hline & C18:3 & $0.3 \pm 0.0$ & $0.2 \pm 0.1$ \\
\hline & SFA & $47.1 \pm 0.9$ & $45.3 \pm 0.8$ \\
\hline
\end{tabular}

Note: C18:1 - oleic acid; C18:2 - linoleic acid; C18:3 - linolenic acid; SFA - saturated fatty acids. All data shown $p>0.05$ compared to control.

The rancidity of the oils, as depicted via PV, serves as an indicator for early oxidation stages of oils. Lipids hydroperoxides are $1^{\circ}$ oxidation products, which are very stable in the absence of metals at ambient temperature. However, the hydroperoxides concentration increases when oxidation takes place and continues rising until it reaches the advanced oxidation stages (Choe and Min, 2006). Low PV is generally an indicator of good quality oil. In this study, both P80 and P120 showed $\mathrm{PV}<10$ meq $\mathrm{O}_{2} \mathrm{~kg}^{-1}$ under heating up to reaction time of $2 \mathrm{hr}$. Palm olein heated at $120^{\circ} \mathrm{C}$ showed more severe PV changes. Significant changes were observed between P80 and P120 from T2 to T12 compared to control; and the highest PV achieved were $29.11 \pm 0.85$ and 57.88 \pm 1.74 , respectively (Figure 4). The maximum acceptance level of the PV for edible oils is 10 milliequivalents of active oxygen per $\mathrm{kg}$ of oil (meq $\mathrm{O}_{2} \mathrm{~kg}^{-1}$ ) according to CODEX STAN 210-1999. The results revealed that thermal oxidation occurred in palm olein under heating at $80^{\circ} \mathrm{C}$ and $120^{\circ} \mathrm{C}$ and became more severe and undesirable under prolonged heating. 


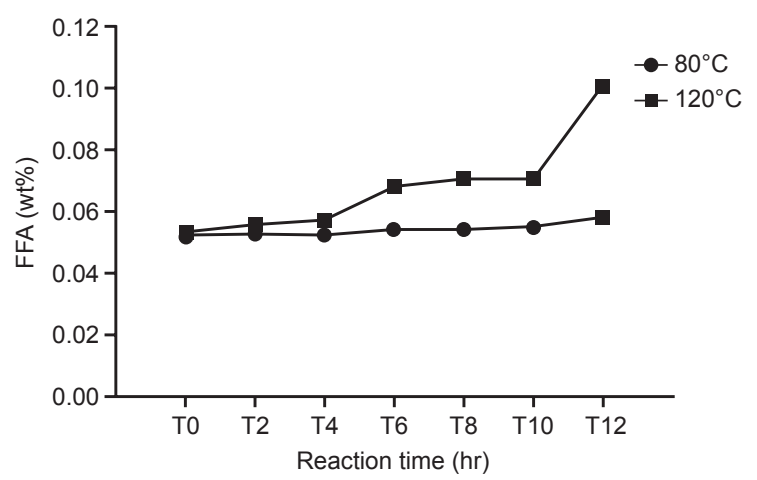

Figure 1. Free fatty acid (FFA) content of palm olein heated at $80^{\circ} \mathrm{C}$ and $120^{\circ} \mathrm{C}$ from 0 to $12 \mathrm{hr}$ (T0, T2, T4, T6, T8, T10 and T12).

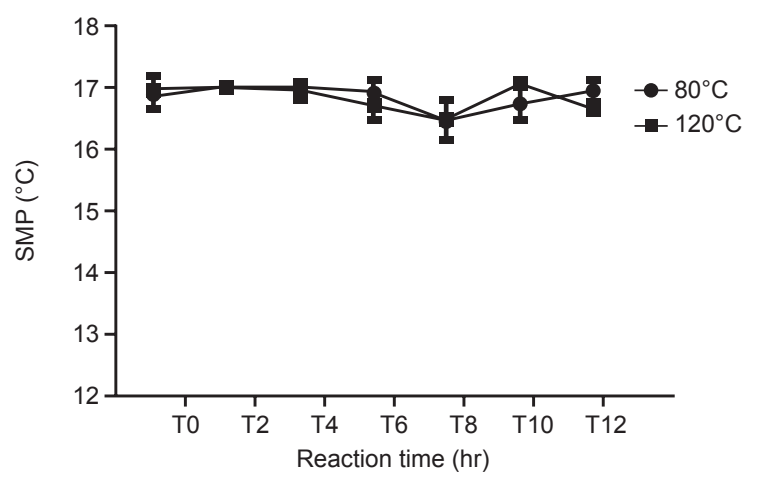

Figure 2. Slip melting point (SMP) of palm olein heated at $80^{\circ} \mathrm{C}$ and $120^{\circ} \mathrm{C}$ from 0 to $12 \mathrm{hr}$ (T0, T2, T4, T6, T8, T10 and T12).

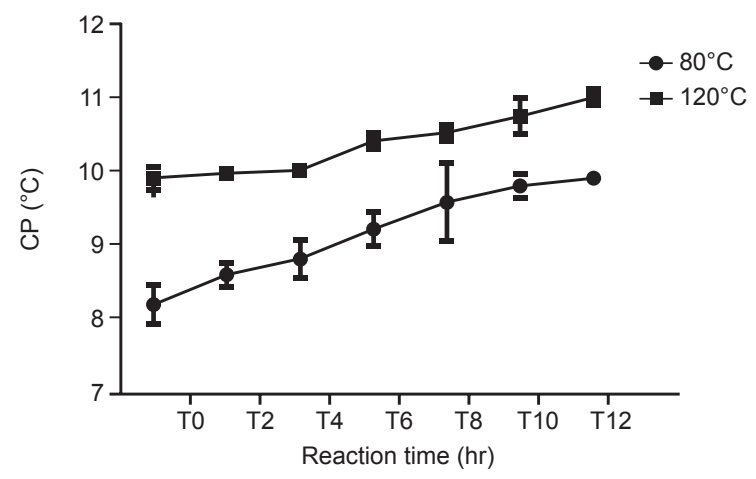

Figure 3. Cloud point (CP) of palm olein heated at $80^{\circ} \mathrm{C}$ and $120^{\circ} \mathrm{C}$ from 0 to $12 \mathrm{hr}$ (T0, T2, T4, T6, T8, T10 and T12).

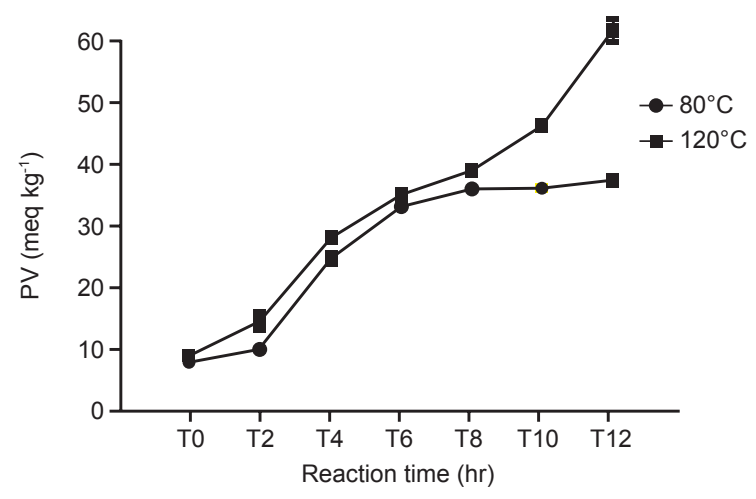

Figure 4. Peroxide value (PV) of palm olein heated at $80^{\circ} \mathrm{C}$ and $120^{\circ} \mathrm{C}$ from 0 to $12 \mathrm{hr}$ (T0, T2, T4, T6, T8, T10 and T12).
TABLE 3. IODINE VALUE (IV) OF PALM OLEIN HEATED AT $80^{\circ} \mathrm{C}$ AND $120^{\circ} \mathrm{C}$ FROM 0 TO 12 hr (T0, T2, T4, T6, T8, T10 and T12)

\begin{tabular}{ccc}
\hline \multirow{2}{*}{ Reaction time (hr) } & \multicolumn{2}{c}{ IV } \\
\cline { 2 - 3 } $\mathbf{8 0}^{\circ} \mathbf{C}$ & $\mathbf{1 2 0}^{\circ} \mathbf{C}$ \\
\hline Control & \multicolumn{2}{c}{$55.8 \pm 0.2$} \\
0 & $56.8 \pm 1.0$ & $56.3 \pm 1.1$ \\
2 & $57.5 \pm 1.3$ & $56.1 \pm 0.9$ \\
4 & $55.5 \pm 0.7$ & $56.2 \pm 1.2$ \\
6 & $55.8 \pm 0.8$ & $55.2 \pm 0.4$ \\
8 & $56.0 \pm 1.1$ & $55.9 \pm 0.8$ \\
10 & $55.8 \pm 0.8$ & $56.2 \pm 0.8$ \\
12 & $56.3 \pm 1.7$ & $56.7 \pm 1.5$ \\
\hline
\end{tabular}

Note: All data shown $p>0.05$ compared to control.

\section{CONCLUSION}

Palm olein, a cooking oil was thermally stable under heating at $80^{\circ} \mathrm{C}$ and $120^{\circ} \mathrm{C}$ within the first $2 \mathrm{hr}$ as was evidenced by the PV measurement. The FFA content of palm olein fell within the acceptance level under prolonged heating for $\leq 10 \mathrm{hr}$ at $80^{\circ} \mathrm{C}$ and $120^{\circ} \mathrm{C}$. Palm olein exhibited good oxidative stability property which was associated with its high SFA content. In short, the changes in the extent of oxidative stability and physico-chemical properties of palm olein depend on the heating time and temperature.

\section{ACKNOWLEDGEMENT}

We would like to thank the Director-General of MPOB for permission to publish this article.

\section{REFERENCES}

Brodnitz, M H (1968). Autoxidation of saturated fatty acids. A review. J. Agric. Food Chem., 16: 994999.

Burenjargal, M and Totani, N (2009). Cytotoxic compounds generated in heated oil and assimilation of oil in Wistar rats. J. Oleo Sci., 58: 1-7.

Choe, E and Min, D B (2006). Mechanisms and factors for edible oil oxidation. Compr. Rev. Food Sci. Food Saf., 5: 169-186.

Ciccone, M M; Cortese, F; Gesualdo, M; Carbonara, S; Zito, A; Ricci, G; De Pascalis, F; Scicchitano, P and Riccioni, G (2013). Dietary intake of carotenoids and their antioxidant and anti-inflammatory effects in cardiovascular care. Mediators Inflamm., 2013: 1-11.

Dabrowska, M; Zielinska, A and Nowak, I (2015). Lipid oxidation products as a potential health and analytical problem. CHEMIK, 69: 89-94. 
Grimm, M O W; Mett, J and Hartmann, T (2016). The impact of vitamin $\mathrm{E}$ and other fat-soluble vitamins on Alzheimer's disease. Int. J. Mol. Sci., 17: 17851802.

Grootveld, M; Silwood, C J L; Addis, P; Claxson, A; Serra, B B and Viana, M (2001). Health effects of oxidized heated oils. J. Foodservice, 13: 41-55.

Hoekman, S K; Broch, A; Robbins, C; Ceniceros, E and Natarajan, M (2012). Review of biodiesel composition, properties, and specifications. Renew. Sust. Energ. Rev., 16: 143-169.

Khurana, S; Venkataraman, K; Hollingsworth, A; Piche, M and Tai, T C (2013). Polyphenols: Benefits to the cardiovascular system in health and in aging. Nutrients, 5: 3779-3827.

Kinsella, J; Shimp, J and Mai, J (1978). The proximate and lipid composition of several species of freshwater fishes. Food and Life Sciences Bulletin, 69: 1-20.

Mahesar, S; Sherazi, S T; Khaskheli, A; Kandhro, A and Uddin, S (2014). Analytical approaches for free fatty acids assessment in oils and fats. Anal. Methods, 6: 4956-4963.

Mayne, S T (1996). Beta-carotene, carotenoids, and disease prevention in humans. FASEB J., 10: 690-701.

Miyake, Y; Yokomizo, K and Matsuzaki, N (1998). Rapid determination of iodine value by $1 \mathrm{H}$ Nuclear Magnetic Resonance spectroscopy. J. Amer. Oil Chem. Soc., 75: 15-19.

Molteberg, E L; Magnus, E M; Bjorge, J M and Nilsson, A (1996). Sensory and chemical studies of lipid oxidation in raw and heat-treated oat flours. Cereal Chem., 73: 579-587.

Ogbe, R J; Ochalefu, D O; Mafulul, S G and Olaniru, O B (2015). A review on dietary phytosterols: Their occurrence, metabolism and health benefits. Asian J. Plant Sci. Res., 5: 10-21.

Ogino, H; Sakazaki, F; Okuno, T; Arakawa, T and Ueno, H (2015). Oxidized dietary oils enhance immediate- and/or delayed-type allergic reactions in BALB/c mice. Allergol. Int., 64: 66-72.

Olivero, D R; Bastida, S; Schultz, A; Gonzalez, T L; Gonzalez-Munoz, M J; Sanche-Muniz, F J and Benedi, J (2010). Fasting status and thermally oxidized sunflower oil ingestion affect the intestinal antioxidant enzyme activity and gene expression of male Wistar rats. J. Agric. Food Chem., 58: 2498-2504.

Otieno, N F; Dai, X; Barba, D D; Bahman, A; Smedbol, E; Rajeb, M and Jaton, L (2016). Palm oil production in Malaysia: An analytical systems model for balancing economic prosperity, forest conservation and social welfare. Agricultural Sciences, 7: 55-69.

Pandey, K B and Rizvi, S I (2009). Plant polyphenols as dietary antioxidants in human. Oxid. Med. Cell. Longev., 2: 270-278.

Redgrave, T G; Kodali, D R and Small, D M (1988). The effect of triacyl-sn-glycerol structure on the metabolism of chylomicrons and triacylglcerol-rich emulsions in the rat. J. Biol. Chem., 263: 5118-5123.

Scalbert, A; Manack, C; Morand, C; Remesy, C and Jimenez, A (2005). Dietary polyphenols and the prevention of diseases. Crit. Rev. Food Sci. Nutr., 45: 287-306.

Shafaeizadeh, S; Jamalian, J; Owji, A A; Azadbakht, L; Ramezani, R; Karbalaei, N; Rajaeifard, A and Tabatabai, N (2011). The effect of consuming oxidized oil supplemented with fiber on lipid profiles in rat model. J. Res. Med. Sci., 16: 1541-1549.

Siew, W L (1990). Palm oil sterols. Palm Oil Developments No. 12: 18-19.

Small, D M (1991). The effects of glyceride structure on absorption and metabolism. Annu. Rev. Nutr., 11: 413-434.

Stahl, W; Heinrich, U; Jungmann, H; Sies, H and Tronnier, H (2000). Carotenoids and carotenoids plus vitamin E protect against ultraviolet light-induced erythema in humans. Am. J. Clin. Nutr., 71: 795-798.

Sutherland, W H; de Jong, S A; Hessian, P A and Williams, M J (2010). Ingestion of native and thermally oxidized polyunsaturated fats acutely increases circulating numbers of endothelial microparticles. Metabolism, 59: 446-453.

Teh, S S; Voon, P T; Ng, Y T; Ong, S H; Ong, A S H and Choo, Y M (2016). Effects of fatty acids at different positions in the triglycerides on cholesterol levels. J. Oil Palm Res. Vol. 28: 211-221.

Tian, K and Dasgupta, P K (1999). Determination of oxidative stability of oils and fats. Anal. Chem., 71: 1692-1698.

Totani, N and Burenjargal, M (2008). Gluten binds cytotoxic compounds generated in heated frying oil. J. Oleo Sci., 57: 683-690.

Wambura, P; Yang, W; Walker, L T and Williams, L (2008). Improvement of oxidative stability of roasted peanuts by edible coatings and ultrasonication. $J$. Food Process. Preserv., 32: 469-485. 